\title{
Nuevo municipio mexicano y reforma del estado
}

Tonatiuh Guillén López ${ }^{1}$

RESUMEN: El objetivo del presente documento es analizar algunos de los elementos principales que actualmente caracterizan al ámbito municipal en México como entidad de gobierno y como aparato de administración pública, determinando un perfil institucional que distingue cualitativamente al municipio contemporáneo en su historia reciente. El foco de la discusión son los municipios mexicanos, porque estos son un excelente ejemplo del protagonismo que la entidad local esta conquistando en la América Latina. En el curso de las últimas dos décadas, el municipio mexicano se ha transformado radicalmente, de tal modo que su estructura interna, sus funciones públicas, sus relaciones con la sociedad y además el conjunto del marco intergubernamental reflejan un perfil distinto, dibujando su nuevo protagonismo en la esfera local mexicana.

PALABRAS CLAVES: municipalidad, reforma del estado, gobierno local

ABSTRACT: The main goal of this paper is to analyze some of the core elements that characterize the current municipality in Mexico as a governmental entity as well as an apparatus of the public administration, while shaping an institutional profile which qualitatively distinguishes the contemporaneous municipality in the recent history. The focus of this debate is the Mexican municipalities because they are an excellent example of the key role that the local entity is increasingly playing in Latin America. In the last two decades, the Mexican municipality has been radically transformed in such way that its internal structure as well as the public functions and consequently its relationship with society and the whole intergovernmental framework, are reflecting a distinctive profile drawing up its new role in the Mexican local level.

KEYWORDS: Mexican municipalities; state reform, local government

\footnotetext{
${ }^{1}$ Profesor Dr. Investigador de El Colegio de la Frontera Norte. E-mail : thonatiuguilhen@yahoo.com
} 
La transición experimentada por el municipio, por otro lado, no es ajena al panorama más amplio del Estado. El nuevo perfil municipal ha implicado afirmar la distinción categórica entre tres órdenes de gobierno en México: el federal, el estatal y el municipal. El balance entre éstos, su respectivo horizonte de responsabilidades y el conjunto de sus relaciones, también han sido alteradas: el histórico centralismo ha dejado de tener vigencia, considerando el peso de los nuevos actores, si bien el proceso apenas comienza y sobreviven poderosas inercias del viejo modelo. Con esa perspectiva, la reforma municipal equivale también a una reforma del Estado, “desde abajo”, en la misma proporción como transcurre la primera. Reformar al municipio equivale directamente a reformar el Estado, no sólo porque el primero forma parte integral del segundo, sino porque la reforma municipal impacta al conjunto de la estructura del Estado y a la posición relativa de cada uno de sus integrantes.

La reforma municipal y el nuevo perfil de la institución configuran y se derivan de procesos complejos, cuyo análisis completo requeriría de un esfuerzo mayor al pretendido por este documento. En esta oportunidad, se ha optado por ofrecer un escenario que de manera genérica describa las características del nuevo municipio $\mathrm{y}$, con un poco de mayor amplitud, se analiza la expansión de las funciones y servicios públicos municipales, que son finalmente la expresión material de sus nuevas capacidades para atender las necesidades colectivas. Desde la perspectiva de las personas y de sus necesidades, lo anterior equivale a reconocer que es cada vez más importante lo que hacen los municipios, en comparación con el papel de los estados y la federación. La pirámide tradicional entre ámbitos de gobierno no se ha invertido, por supuesto, lo que es particularmente evidente en la distribución de los recursos económicos y el sistema fiscal nacional. Lo que destacamos es el firme inicio del movimiento del péndulo en dirección hacia la descentralización. Uno de los mejores indicadores de este proceso es justamente la ampliación de los servicios y funciones públicas municipales, que de un número limitado y atendido con recursos menores, se ha extendido sobre terrenos que usualmente eran cubiertos por la federación o los estados. Para este análisis se utiliza la base de datos del Premio Gobierno y Gestión Local (www.premiomunicipal.org.mx), que constituye la fuente más completa y actualizada en la materia. 


\section{El nuevo municipio mexicano}

Durante las últimas dos décadas, el municipio en México ha experimentado una intensa evolución que consolida su presencia en la estructura del Estado y tiende a modernizar su integración como gobierno y como aparato público responsable de ampliadas funciones y servicios. La magnitud de este cambio delimita una nueva etapa en la historia de la institución municipal, un giro de profundidad cualitativa, que justifica referirnos a éste como nuevo municipio mexicano.

\section{Fase primaria de la autonomía}

Son de distinta naturaleza los procesos involucrados alrededor del nuevo perfil del municipio. Por una parte, aquellos relativos a la determinación política del gobierno municipal, que posibilitan ahora un sustento básico para el ejercicio de su autonomía, que a su vez deriva de la democracia local. A diferencia del período previo, de corte autoritario, centralista y en donde el gobierno municipal se encontraba sujeto en aspectos esenciales a poderes externos -como los gobiernos de los estados o directamente de instancias del poder federal-, la nueva etapa encuentra en la democracia local su cimiento. La determinación política propia ha tenido un rol fundamental para establecer la distinción y separación entre ámbitos del gobierno, generando un espacio específico para la institución municipal.

En la época previa, el municipio en la práctica guardaba una relación de subordinación política y administrativa ante los estados y las dependencias federales, que en ocasiones incidían hasta en las más mínimas de sus decisiones. Precisamente, la capacidad de decidir por sí mismo es uno de los indicadores más contundentes sobre la autonomía municipal y su progresiva consolidación en el marco intergubernamental. De esta capacidad depende su existencia como entidad gubernamental en sí misma. Por este motivo, la fuente de última instancia sobre la decisión municipal, oscilando entre lo externo y lo interno, constituye una diferencia cualitativa de gran relevancia entre un periodo y otro de la evolución municipal. La nueva capacidad política posibilita al municipio reivindicar su rol como gobierno y como entidad específica del Estado. ${ }^{2}$

2 En el marco jurídico de México, especialmente en las constituciones del país y en las respectivas de los estados, el escenario descrito ha tenido su propio modo de expresión con el debate entre definir al municipio como entidad "administrativa" o como "gobierno", implicando en el primer sentido una relación de subordinación ante los gobiernos de los estados, mientras que la segunda reivindica a una 


\section{Fase primaria de las relaciones intergubernamentales}

Con la nueva base política disponible para el ejercicio de su autonomía, así fuera en sus rasgos esenciales, los cambios del municipio pudieron extenderse al marco intergubernamental, en donde reclamó el reconocimiento de su personalidad como instancia de gobierno e interlocutor necesario para los estados y la federación. Las tensiones y el abierto conflicto en muchas ocasiones fueron una constante en un marco intergubernamental en el que por primera vez surgía el municipio con una posición propia, ejerciendo sus atribuciones con la mayor autonomía posible. La entidad local inevitablemente debió confrontarse con una histórica inercia de subordinación reflejada no solamente en las conductas de determinados funcionarios públicos, sino además en programas y acciones de los estados y de la federación, que asumían su posición no protagónica y habitualmente dócil.

Los municipios, antes que los estados, fueron pioneros en la apertura de las relaciones intergubernamentales en sentido estricto, lo cual fue sin duda catalizado por la alternancia política y en general por las diferencias de partido entre los gobiernos municipales y los correspondientes a estados y federación. Con su iniciativa, de hecho, fueron los generadores de lo que ahora son las relaciones intergubernamentales, en la medida en que antes lo que existía era una cadena de mando vertical, con capacidad para anular toda disidencia.

En este aspecto, es conveniente destacar el papel de la pluralidad y de la alternancia políticas como factores que catalizan el surgimiento de un marco intergubernamental inédito en México. No obstante, el proceso no se reduce un asunto entre partidos políticos. Detrás de tensiones y conflictos, acuerdos y coordinación, no se encuentran únicamente los intereses de los partidos ni las expresiones de su competencia. Lo más relevante es que por su intermedio emerge un interés institucional que trasciende a los actores inmediatos. Dicho de otra manera, sobresale una agenda municipal, que tanto enfoca objetivos estructurales de la reforma del Estado desde el interés local, como otros inmediatos que surgen del entorno propio del municipio. A pesar de la evidente presencia de los partidos y de sus intereses, en

entidad pública que surge de sí misma, sustentada en la soberanía popular y en el ejercicio democrático de ésta. Actualmente, la constitución del país define al municipio como "gobierno", si bien todavía de manera sutil, lo cual fue logrado mediante la reforma constitucional de 1999 (Artículo 115). 
la negociación intergubernamental éstos no tienen legitimidad alguna, ni pertinencia. En el discurso y en la forma están obligados a expresar únicamente a la agenda institucional, que alcanza prioridad incluso en aquellas coyunturas fuertemente estimuladas por el conflicto entre partidos.

Durante los años noventa, se generó así el espacio para las relaciones intergubernamentales y para la política intergubernamental, es decir, para la expresión y negociación de agendas institucionales específicas, lo cual también es una innovación derivada de la reforma municipal. Como toda innovación, la política intergubernamental no surgió en un espacio institucional definido, como tampoco con procedimientos acordados entre las partes. En el proceso se generaron sus actores, su respectiva agenda de intereses, pero no el lugar institucional para dirimir las diferencias, muchas de profundidad estructural. La opinión pública y sus instrumentos, el diálogo bilateral cuando fue factible, en otras ocasiones los tribunales judiciales, son prácticas aún vigentes en donde se refleja la nueva política intergubernamental.

La agenda municipal construyó a sus actores principales en las asociaciones de municipios, que paradójicamente tienen el estatus jurídico de asociaciones civiles, no obstante su evidente naturaleza gubernamental.3 Primero se constituyó la Asociación de Municipios en México (AMMAC); posteriormente la Asociación de Autoridades Locales de México (AALMAC) y después la Federación Nacional de Municipios de México (FENAMM). Actualmente las tres asociaciones, junto con otras de menor dimensión, colaboran hacia su integración en una Conferencia Nacional del Municipio de México, la cual tendría el potencial de negociar mejores términos la agenda de los municipios del país. De manera paralela a la consolidación de estas asociaciones, la agenda municipal definió sus rubros prioritarios, entre los que se encuentran demandas en materia de descentralización, reequilibrio fiscal y mayores transferencias, mejores bases para la cooperación y coordinación, la reelección inmediata de autoridades locales, entre otros rubros importantes.

\footnotetext{
${ }^{3}$ Esta situación refleja la incapacidad y anacronismo del sistema legal vigente para reconocer a la política intergubernamental y a sus actores, no obstante la vigencia de un sistema federal del Estado que necesariamente requiere de esta negociación en su funcionamiento.
} 


\section{Fase primaria de la democracia local}

Por otra parte, con el nuevo sustento democrático, la ruta de los cambios del municipio incluyen a las relaciones entre sociedad y gobierno municipal, que no solamente se refieren a los procedimientos de la democracia en su fase electoral, sino que progresivamente pugnan por modernos modelos de democracia participativa y deliberativa, además de espacios complementarios en la esfera de la gestión pública, incluyendo la corresponsabilidad operativa de determinadas funciones y servicios. En México, la apertura política y la transición democrática dieron sus primeros pasos en los municipios, de manera generalizada a partir de 1983. Conforme a su consolidación, las sociedades locales invirtieron la relación política previa con sus autoridades: por vez primera lograron determinarlas, decidirlas, estableciendo la base primaria del autogobierno local. El vínculo entre sociedad y gobierno local pudo así estrecharse y evolucionar hacia prácticas democráticas, que desbordan al previo lazo de corte autoritario y distante.

Si bien no ha concluido, esta reforma fue de gran profundidad y de giro cualitativo, que también distingue al nuevo municipio de su larga historia previa. Desde la perspectiva de la sociedad fue la conquista de su ciudadanía, en la práctica y ya no sólo en los enunciados legales, así como la construcción del espacio electoral como la arena para decidir a la política. Desde la perspectiva del gobierno local, la democracia significó la posibilidad de su existencia como gobierno propio y para el ejercicio de su autonomía. Cabe añadir, sobre la democracia municipal, que como otros elementos del nuevo municipio también se encuentra en una fase inicial. La agenda pendiente de reformas en esta materia incluye rubros sustantivos como la calidad de la representación política local y de sus actores, la integración de los ayuntamientos, así como la reforma de los procesos de decisiones para abrir espacio a la democracia deliberativa y participativa, entre otros aspectos fundamentales. El círculo democrático no ha terminado de cerrarse.

Junto con la democracia, la alternancia política en los gobiernos municipales es otro de los rasgos característicos del nuevo municipio mexicano. Frente a la larga historia de municipios asociados al sistema político de partido único, del Partido Revolucionario Institucional (PRI), actualmente es una norma cotidiana que distintos partidos ocupen los cargos de elección en los ayuntamientos. La consecuente competitividad política, ha sido un estímulo fundamental para la evolución de los gobiernos y administraciones 
municipales, a lo cual se suma la influencia de una constante demanda ciudadana que tiene ahora mejores condiciones para expresarse, tanto a partir de sus organizaciones ciudadanas y sociales, como mediante corrientes de opinión pública. El resultado son así nuevos actores, factores y condiciones que han impulsado el dinamismo municipal en su conjunto.

\section{Municipalización de la agenda pública y ampliación de funciones}

Adicionalmente, de cumplir con servicios públicos de escaso número y con reducidos recursos materiales y humanos, la nueva etapa se caracteriza por una notable ampliación del espectro de funciones y servicios, su especialización operativa, por la magnitud de los recursos involucrados y, sobre todo, por la capacidad municipal para atender directamente relevantes necesidades del agenda pública local. En este aspecto se condensan los efectos de la transición democrática, la pluralidad y competitividad política, los nuevos actores de la política local, así como la presencia constante e insistente de una demanda ciudadana que identifica su agenda pública de necesidades y presiona a los municipios para su atención. Visto el escenario en su conjunto, puede éste describirse como la construcción de una agenda pública local, tan diversa como la heterogeneidad de los municipios del país, derivada de un mayor y mejor espacio para su expresión y, especialmente, para su inducción sobre el gobierno local. Si la democracia local tiene un efecto, es justamente en su capacidad para definir una agenda propia de necesidades colectivas en los municipios y, en segundo término, para su inserción en la agenda de los gobiernos locales. Tan exitosa es una democracia local, como eficiente sean las condiciones de este proceso.

Los municipios mexicanos reflejan esta última dinámica, en muy distintas condiciones de eficiencia y con excepcional diversidad. La construcción e inserción de la agenda pública local en los gobiernos y administraciones municipales explica el dinamismo de éstas últimas y, particularmente, los rasgos más notables de su evolución reciente. Entre los más destacados, la ampliación de las funciones y servicios públicos atendidos, los cuales han asumido por iniciativa propia, sin ser necesarias explícitas disposiciones de descentralización proveniente de los estados o del gobierno federal. El proceso puede denominarse como una "descentralización de facto", derivada de la apropiación del municipio de su respectiva agenda de necesidades públicas. De este modo, en los últimos tres lustros los municipios han ampliado progresivamente su lista de responsabilidades, 
incursionando en áreas y funciones que antes ni siquiera eran aludidas como problemáticas locales. La nueva lista incluye aspectos fundamentales de los asuntos públicos, como la política social, el desarrollo económico, los temas ambientales, el desarrollo urbano, la promoción de la vivienda, salud, educación, políticas culturales, entre otras más.

La ampliación de sus funciones y servicios se ha convertido así en uno de los rasgos característicos del nuevo municipio mexicano. No todos los municipios del país con igual intensidad, ni con los mismos aspectos de política pública local, por supuesto, dada su heterogeneidad en sus dimensiones y condiciones sociales, económicas, regionales y culturales. No obstante, en todos los casos se reitera el eje central del proceso: que la dinámica responde a la progresiva apropiación por las sociedades locales de su respectiva agenda pública de necesidades, lo cual ha sido posibilitado por las nuevas condiciones democráticas, no obstante las limitaciones que todavía contiene la democracia local. Las administraciones municipales reflejan los alcances de esta apropiación, tanto como sus limitaciones.

A pesar de que las políticas formales de descentralización en México están prácticamente estancadas o con escasas iniciativas, es decir aquellas promovidas desde la federación o los estados, en la práctica los municipios han extendido su espectro de responsabilidades y, en lo que toca a sus atribuciones formales (y tradicionales), éstas han evolucionado hacia funciones administrativas mucho más especializadas y complejas de operación en comparación con los lustros precedentes. La descentralización de facto ha sido una dinámica mucho más consistente, evidente y con resultados que directamente se asocian a las condiciones cotidianas de vida de las sociedades municipales.

Para medir los alcances de la descentralización de facto y, por su intermedio, la dinámica de apropiación de las agendas locales por sus actores sociales y gobiernos, el Premio Gobierno y Gestión Local constituye un observatorio privilegiado. A partir del 2001, el Premio ha convocado a los gobiernos locales del país a concursar sus programas de mayor calidad, acumulando 2210 programas hacia el 2005. En éstos puede apreciarse tanto una evolución técnica, de interacción social, de redes intergubernamentales y, particularmente, de ampliación de la gestión pública local en función de su diversidad temática. Tenemos así la posibilidad de medir la ampliación de funciones y servicios municipales, la cual constituye un dato central para evaluar el nuevo protagonismo de los municipios en la

CADERNOS GESTÃO PÚBLICA E CIDADANIA, V. 11, N. 48 - JAN/JUNHO 2006 
agenda pública local y, por añadidura, en la agenda de los asuntos nacionales. De manera más detallada, abordaremos el análisis de la nueva configuración de las responsabilidades municipales.

Cabe anticipar que el nuevo municipio mexicano no está asumiendo la totalidad de los asuntos públicos nacionales, evidentemente. Se encuentra construyendo una esfera nueva de intereses que en conjunto definen una esfera municipal de necesidades colectivas, no exenta de tensiones con los órdenes de gobierno estatal y federal. El marco jurídico del país ha sido poco flexible para reconocer los alcances de este reacomodo, que obligan a redefinir el mapa de responsabilidades entre los tres órdenes de gobierno y, especialmente, obligan a la flexibilidad y modernización de sus mecanismos e instancias para la cooperación y coordinación.

El nuevo municipio mexicano, en suma, se caracteriza actualmente por constituir una esfera de gobierno en sí misma, surgida de sí, estableciendo en consecuencia un nuevo balance en la estructura del Estado mexicano, ubicándose en el mismo paralelo que el orden de gobierno federal y de los estados. ${ }^{4}$ De este modo, con mayor claridad que nunca, el Estado mexicano está integrado por tres ámbitos de gobierno, lo cual implica adaptaciones importantes al marco constitucional del país y del federalismo en particular. Por lo pronto, con su nueva presencia, la evolución del municipio equivale también a una reforma del Estado “desde abajo”, modificando el número, la estructura y las relaciones de sus componentes fundamentales.

Cabe advertir que la evolución descrita del municipio se encuentra en una etapa inicial, sin duda sustantiva, pero al mismo tiempo inconclusa. En muchos de sus aspectos es mejor referirse a ellos como "trayectorias", a movimientos en curso, y menos a productos consolidados. En la escala de tiempos de las instituciones, 15 o 20 años son pocos: suficientes para identificar la metamorfosis, escasos para diseñar a la mariposa y a su primavera.

Artigo recebido em 20/10/2004. Aprovado em 20/03/2005.

\footnotetext{
${ }^{4}$ Lo cual no equivale a las mismas atribuciones, ni a los mismos recursos, por supuesto; nos referimos al paralelo jurídico entre ámbitos el gobierno, distinguibles entre sí.
} 